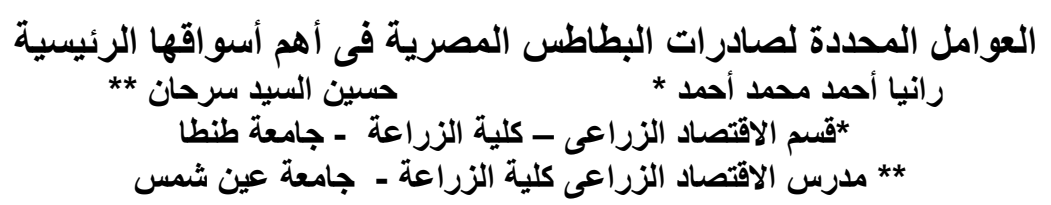

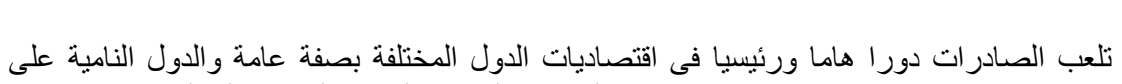

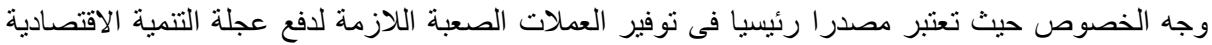

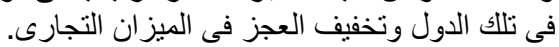

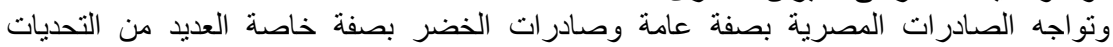

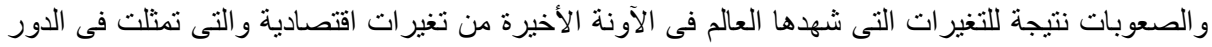

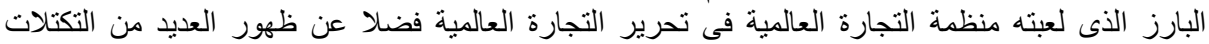

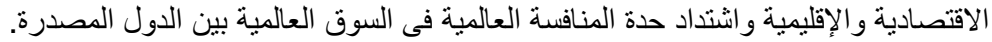

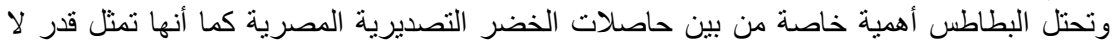

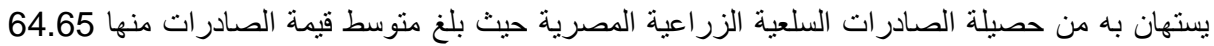

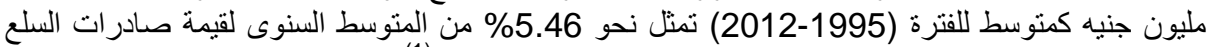

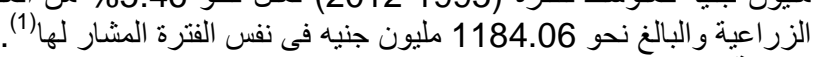

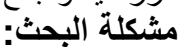

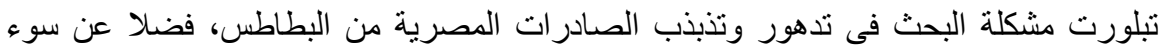

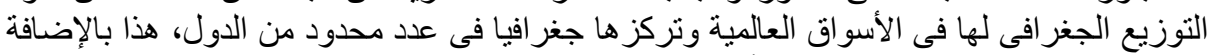

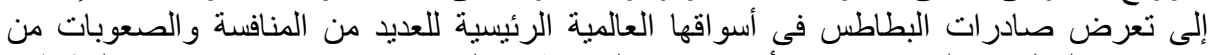

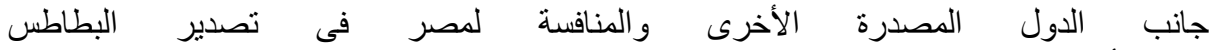

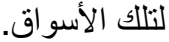

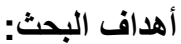
استهدف البحث بصفة البهة رئيسية ما يلى:

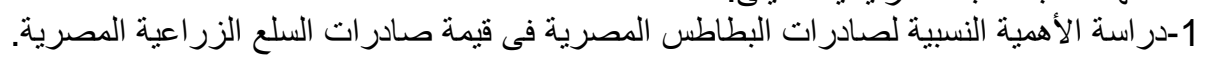

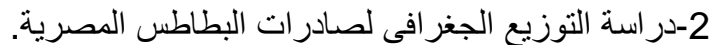
3-الوقوف على أهم العوامل الهحددة لصنادرات البطاط البطس المصرية الهرية فى أهم أسواقها الاستيرادية

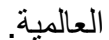
الأسلوب البحثى ومصادر البياتات:

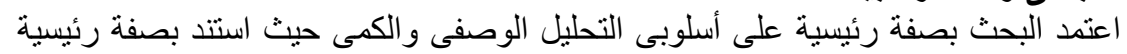
على أسلوب الانحدار المتعدد والانحدار المرحلى فى كل من صورنيه الخطية و اللوغاريتماتية وقد اعتمد البحث على العديد من المصادر على شبكة المعلومات الدولية للجهات الرسمية المزدوجة. التالية: 1 1-موقع الجهاز المركزى للتعبئة العامة والإحصاء

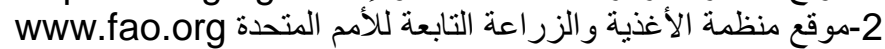

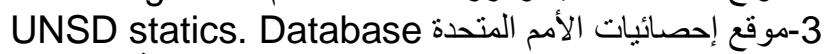
النتائج البحثية

أولا: الأهمية النسبية لصادرات البطاطس فى صادرات البلع الزبلة الزراعية: أ ـالأهمية النسبية لكمية صادرات البطاطس فى كمية صادرات النية السلع الزراعية: 
بدر اسة تطور كمية صادر ات البطاطس فى الفترة (1995-2011) و الموضحة بالجدول رقم

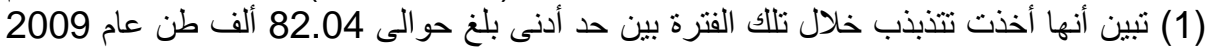

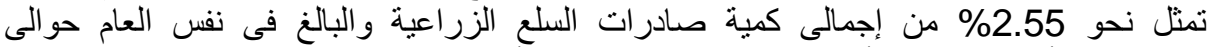

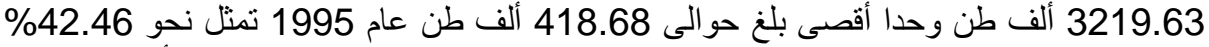

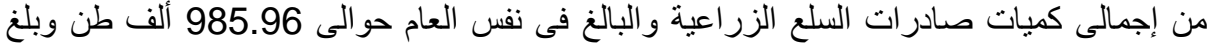

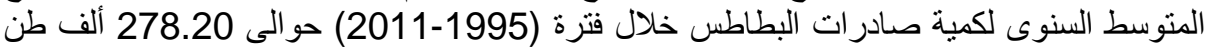

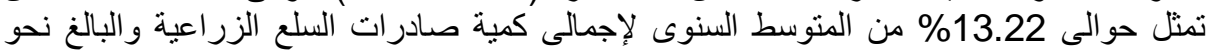
2103.88 ألف طن خلال نفس الفترة.

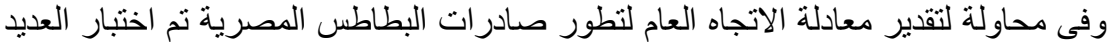

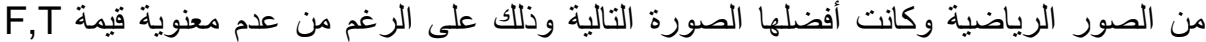

$$
\begin{array}{r}
\hat{Y}=490.916-96.873 X+11.400 X^{2}-0.391 X^{3} \\
(3.597)^{\star *}(-1.405) \quad(1.405) \quad(-1.316) \\
R^{2}=0.165 \quad F=0.857
\end{array}
$$

وتثير المعادلة السابقة إلى أن كمية صادرات البطاطس قد حققت زيادة سنوية غير معنوية.

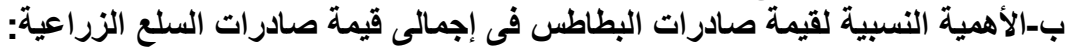

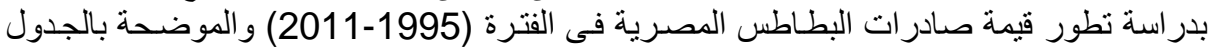

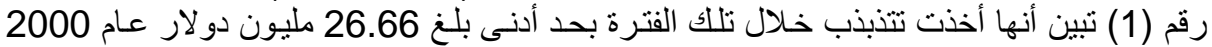

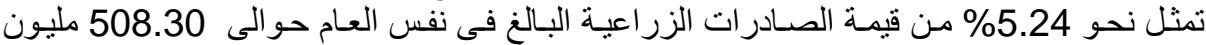

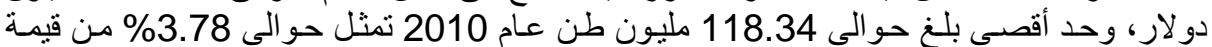

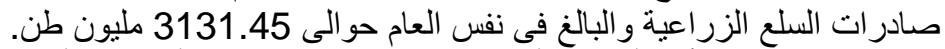

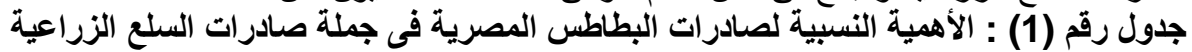

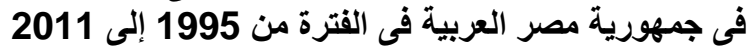

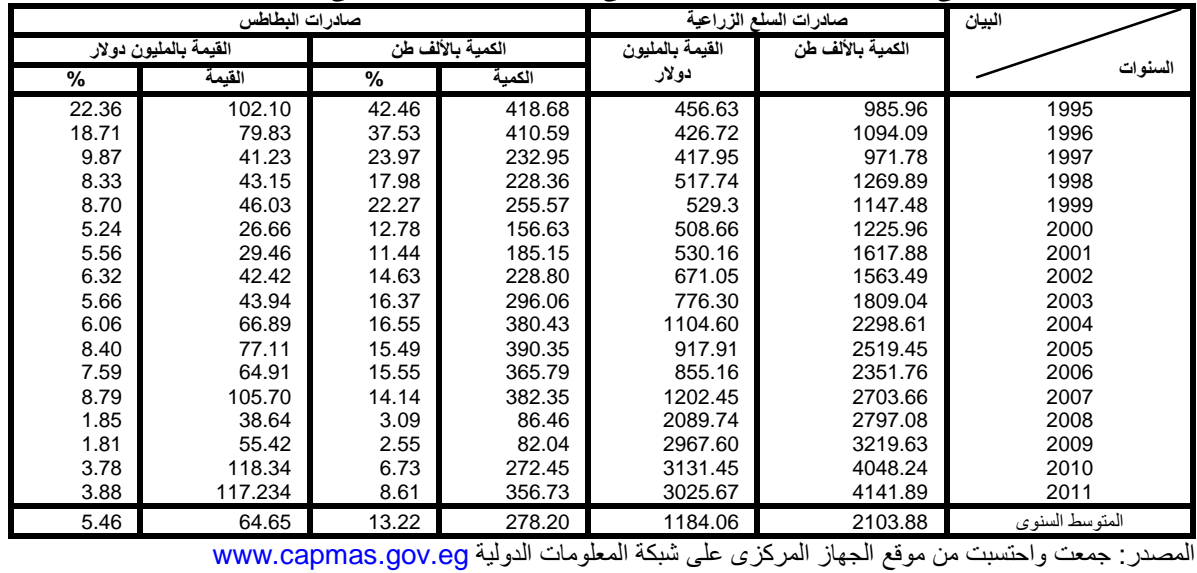

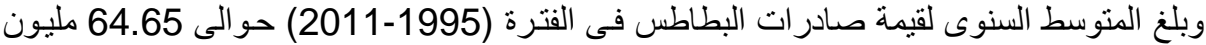
جنيه تمثنل نحو 5.46\% من قيمة صادر ات السلع الزر اعية و البالغ في نفس الفترة حو الى 1184.06

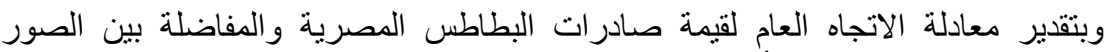

$$
\text { مليون دو لار. }
$$
الرياضية المختلفة للمعادلات جاءت أفضل معادلة على الصورة التكعيبية التالية:

$\hat{Y}=121.072-29.361 X+3.003 X^{2}-0.080 X^{3}$

$(4.530)^{* *} \quad(-2.355)^{*} \quad(1.912) \quad(-1.384)$

$$
\mathrm{R}^{2}=0.59 \quad \mathrm{~F}=(6.227)^{* *}
$$


وتثير المعادلة السابقة إلى أن قيمة صادر ات البطاطس قد حققت زيادة سنوية معنوية بلغت

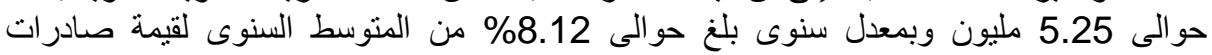
البطاطس خلال الفترة المشار إليها آنفا.

ثانيا: التوزيع الجغرافى لصادرات البطاطس المصرية:

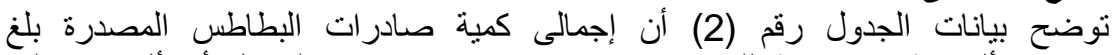

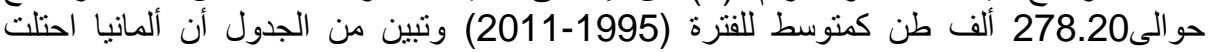

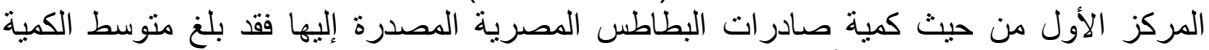

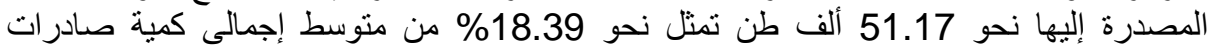

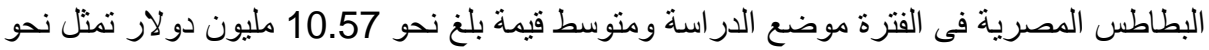

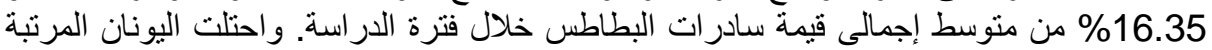

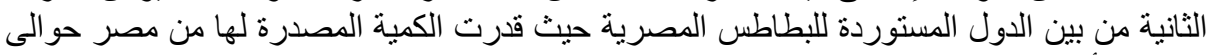

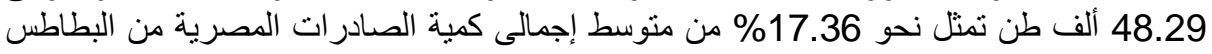

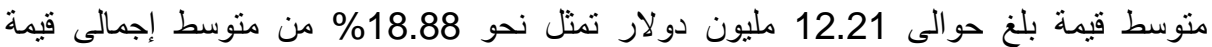

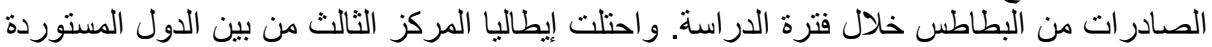

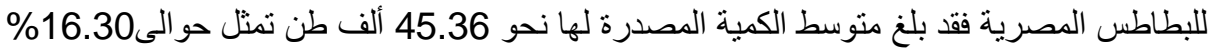

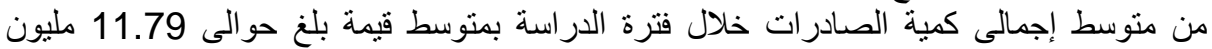

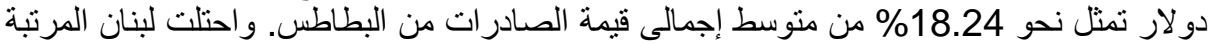

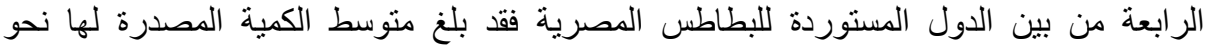

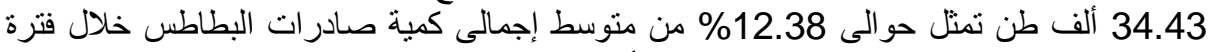

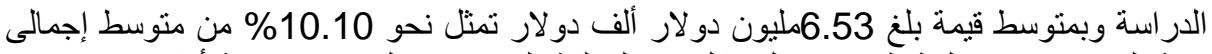

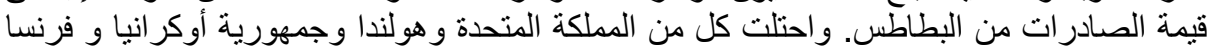

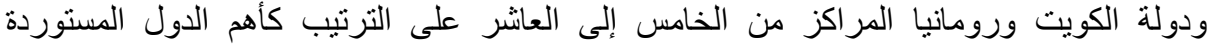

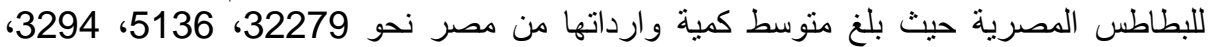

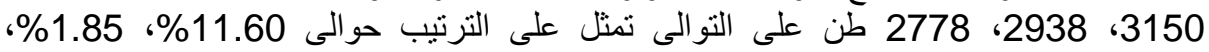

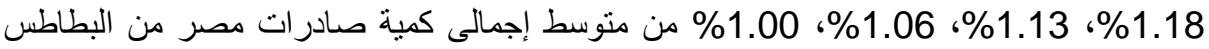

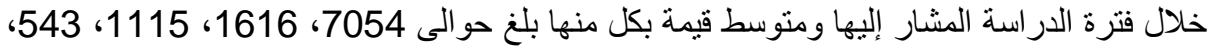

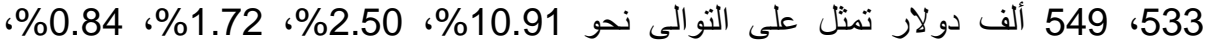
0.83\%، 0.85\% من متوسط إجمالى قيمة الصادر ات المصرية من البطاطس خلال فترة الدر اسة (2011-1995)

واحتلت كل من دولة الإمارات العربية، جمهورية أوكرانيا، عمان، جمهورية روسيا

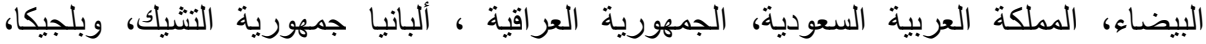

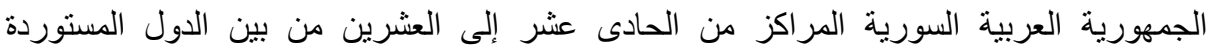

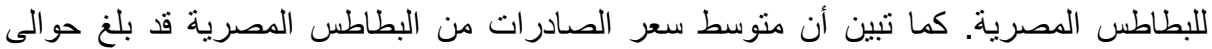

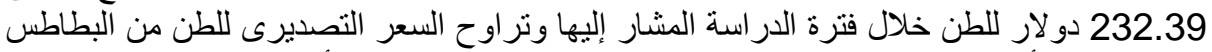

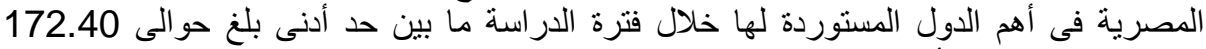
دو لار فى فرنسا وحد أقصى بلغ نحو 241.20 دولار للطن فى الجمهورية العربية السورية. 
جدول رقم (2): التوزيع الجغرافى لصادرات البطاطس المصرية كمتوسط للفترة (1995-2011)

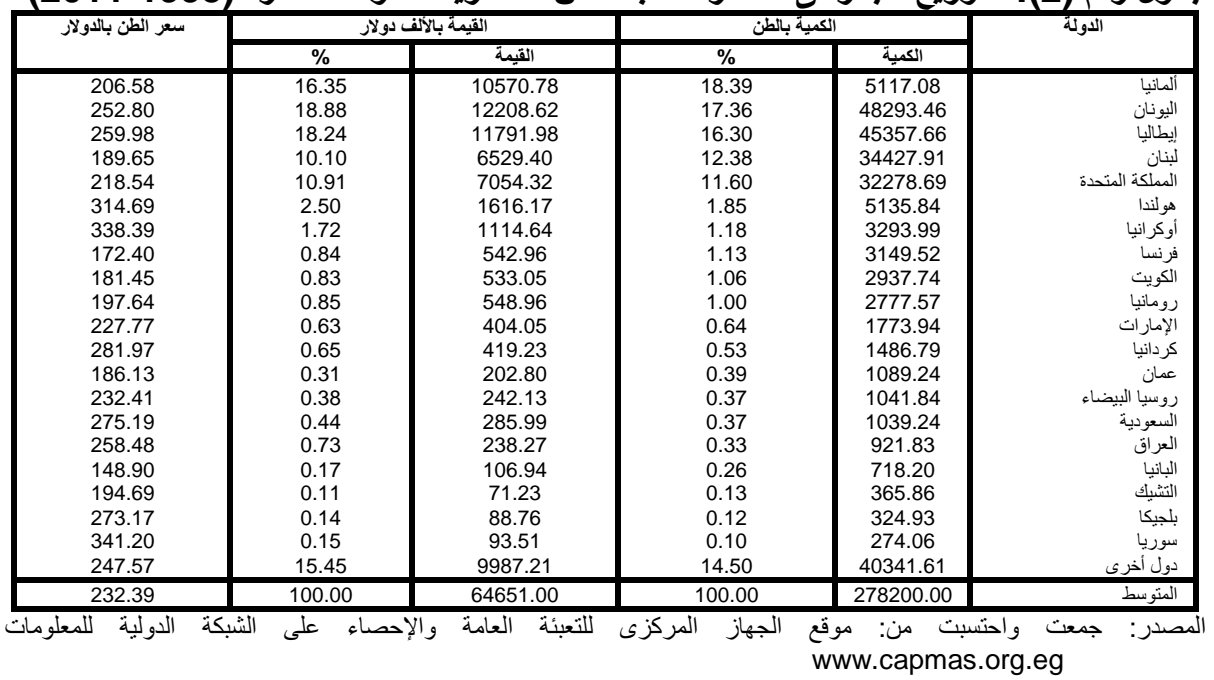

\section{ثالثا: العوامل المحددة لصادرات البطاطس المصرية في أهم أسواقها الرئيسية:}

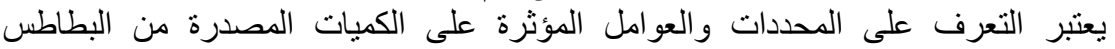

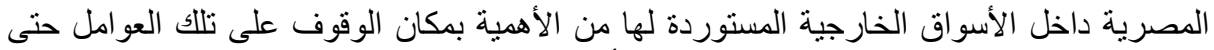

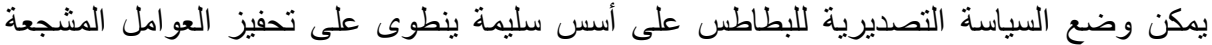

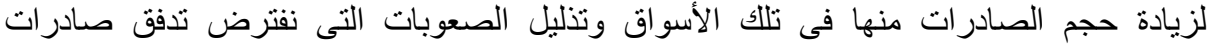

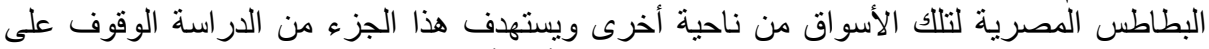

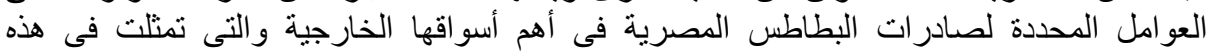

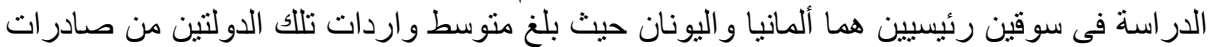

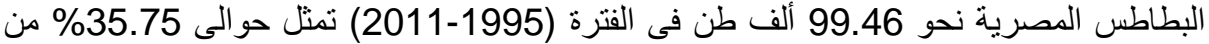

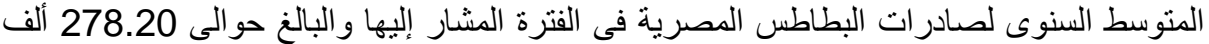
طن جدول رقم (2). وقد نم التوصل لأهم العو امل المحددة للطلب على صادرات البطاطس المصرية فى كل من

تللك الدولتين من خلال النموذجين التاليين:

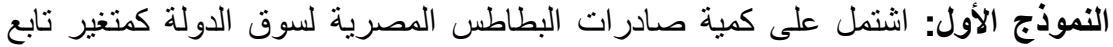

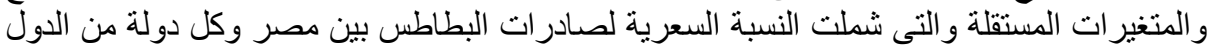

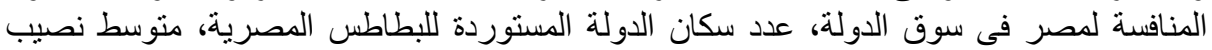

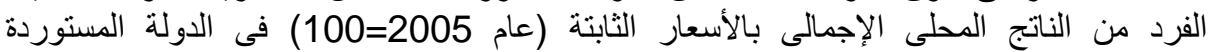
للبطاطس المصرية، سعر صرف الدولار لإن بالجنيه المصرى.

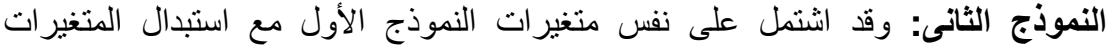

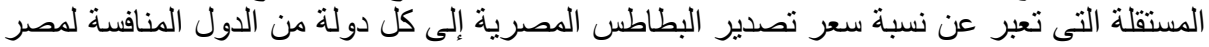

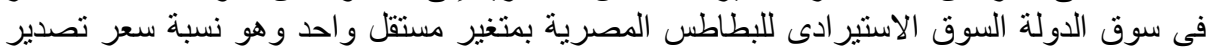

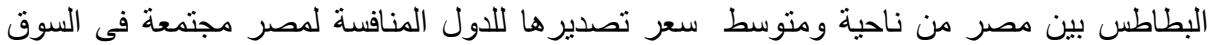
الاستير ادى للبطاطس المصرية.

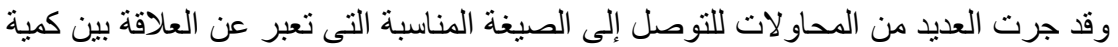

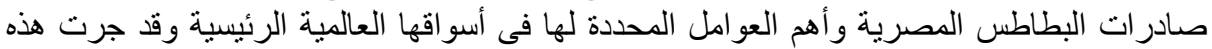

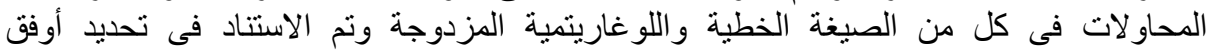
المحاو لات للتعبير عن تلك العلاقة إلى ما يلى: 


$$
\text { 2-1 1-متفوية المعادلة ككل استنادا إلى قيمة (ف). }
$$

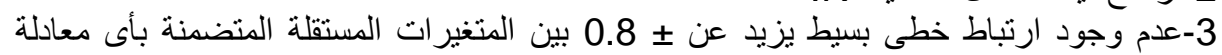

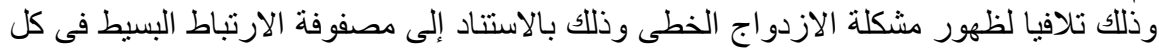

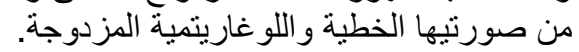

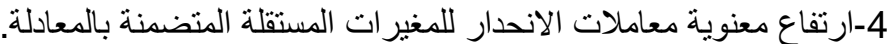

5-أن تكون إثنار ات معاملة معاملات الانحدار للمتغيرات المستقبلة المتضمنة بالمعادلة بالة منمشية مع المنطق الاقتصادى.

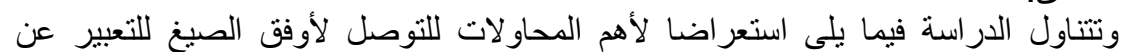

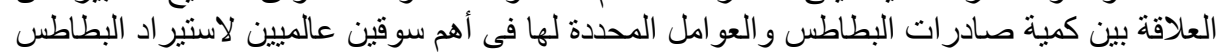

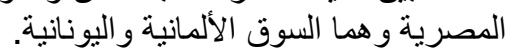

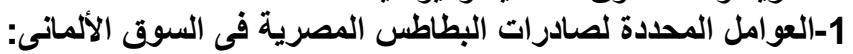

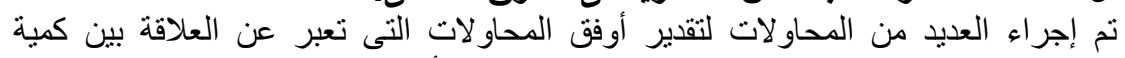

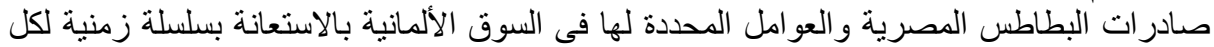

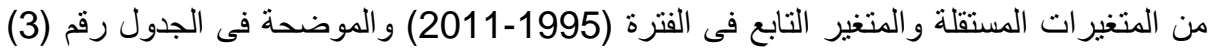

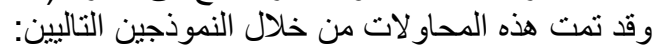
$\wedge$

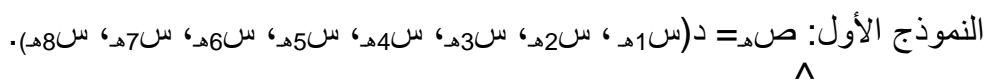

$$
\begin{aligned}
& \text { النموذج الثاني : صهـ = د(س6هـ ، س7هـ ، سههـ ، سوهـ) } \\
& \text { حيث تشير: }
\end{aligned}
$$

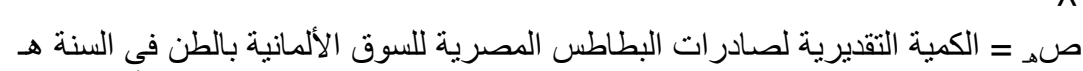

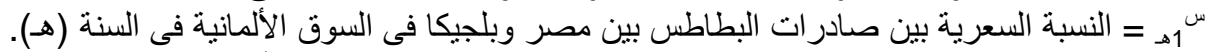

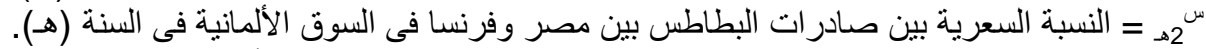

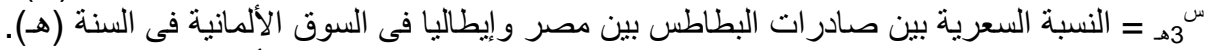

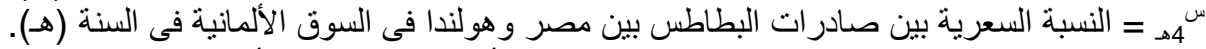

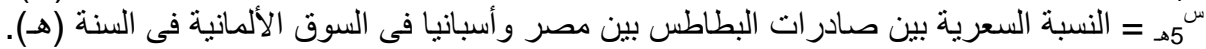

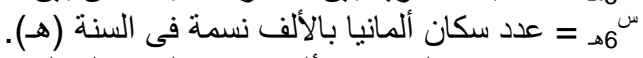

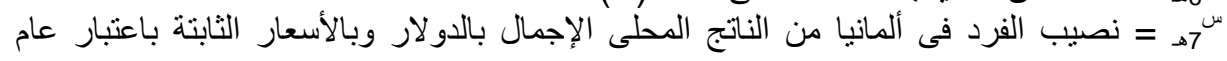
100 =2005

سهـ = سعر صرف الدولار بالجنيه المصرى فى السنة هـ

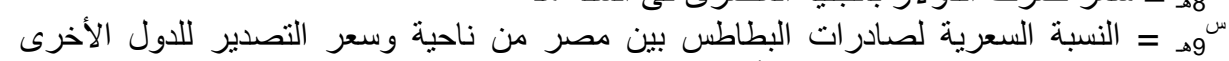

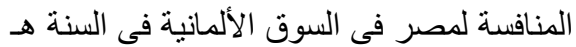

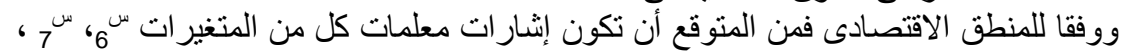

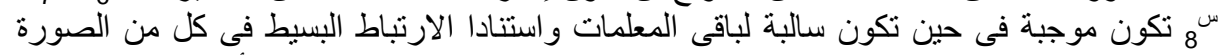

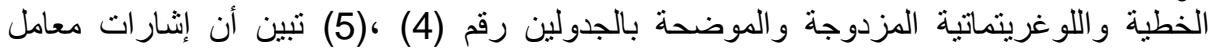

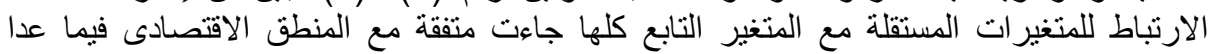

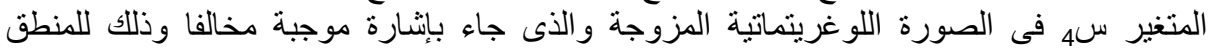

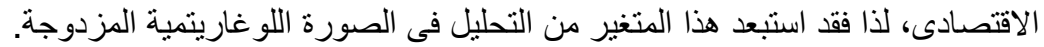

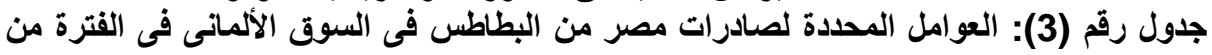
1995 
زانبا أحمد محد أحمد و حسين السيا سرحان

\begin{tabular}{|c|c|c|c|c|c|c|c|c|c|c|}
\hline \multirow{2}{*}{ للبطاطس (2) النسبة } & \multirow{2}{*}{ الثرف } & \multirow{2}{*}{ الالكيانى(1) الفرد } & \multirow{2}{*}{ بلالالفة } & \multicolumn{5}{|c|}{ النسبة السعرية لصلادرات البطاطس فى السوق الألمانية بين } & \multirow{2}{*}{ الصالطرات } & \multirow{2}{*}{ السنوات } \\
\hline & & & & مصر /أسبانيا & مصر /هولندا & مصر / إيطاليا & مصر / فرنسا & مصر / بلجيكا & & \\
\hline 0.935437 & 3.392 & 29449.8 & 83148 & 0.828516 & 1.204482 & 0.765125 & 0.865191 & 0.849802 & 62034 & 1995 \\
\hline 0.884892 & 3.392 & 29596.8 & 83389 & 0.635659 & 1.255102 & 0.745455 & 0.629156 & 0.452206 & 71700 & 1996 \\
\hline 1.461883 & 3.389 & 30074.2 & 83491 & 1 & 2.546875 & 0.883469 & 0.926136 & 0.683438 & 34646 & 1997 \\
\hline 1.176923 & 3.388 & 30630.5 & 83501 & 0.763092 & 1.865854 & 0.836066 & 0.786632 & 0.6 & 61106 & 1998 \\
\hline 1.449640 & 3.395 & 31207.4 & 83491 & 1.409091 & 1.665289 & 1.399306 & 1.119444 & 1.141643 & 46037 & 1999 \\
\hline 1.585000 & 3.472 & 32117.6 & 83512 & 1.219231 & 2.383459 & 1.174074 & 0.987539 & 1.354701 & 17501 & 2000 \\
\hline 1.241617 & 3.93 & 32612.7 & 83583 & 0.748744 & 2.292308 & 0.78836 & 0.871345 & 0.892216 & 25427 & 2001 \\
\hline 1.542986 & 4.50 & 32576.2 & 83685 & 1.306513 & 2.066667 & 1.332031 & 0.909333 & 1.118033 & 28634 & 2002 \\
\hline 1.258964 & 5.851 & 32647.8 & 83188 & 0.814433 & 1.926829 & 0.719818 & 1.097222 & 1.019355 & 33905 & 2003 \\
\hline 1.160920 & 6.196 & 32766.8 & 83849 & 0.865096 & 1.669421 & 0.816162 & 0.766603 & 1.77193 & 36784 & 2004 \\
\hline 1.501691 & 5.779 & 32996 & 83836 & 1.268212 & 2.293413 & 0.832609 & 0.903302 & 1.348592 & 45438 & 2005 \\
\hline 1.155673 & 5.733 & 34256.1 & 83740 & 0.764398 & 1.646617 & 0.860511 & 0862205 & 1.149606 & 24936 & 2006 \\
\hline 0.806061 & 5.635 & 35444.1 & 83579 & 0.730769 & 0.987624 & 0.682051 & 0.671717 & 0.799599 & 30450 & 2007 \\
\hline 0.930085 & 5.433 & 38913.5 & 83380 & 0.664145 & 1.143229 & 1.004577 & 0.834601 & 0.885081 & 3400 & 2008 \\
\hline 1.283920 & 5.545 & 34148.3 & 83183 & 1.009881 & 1.714765 & 0.962335 & 1.228365 & 1.089552 & 7415 & 2009 \\
\hline 1.203883 & 5.622 & 35587.4 & 83017 & 0.877876 & 1.545171 & 0.833613 & 1.156177 & 1.046414 & 5450 & 2010 \\
\hline 1.597647 & 5.933 & 36828.7 & 82893 & 1.441614 & 2.16242 & 1.098706 & 1.113115 & 1.786842 & 2092 & 2011 \\
\hline
\end{tabular}

(1) ونصيب الفرد الألماني من الناتج المحلى الإجمالي باعتبار سنة 2005 =100 (2) النسبة السعرية لصادرات البطاطس بين

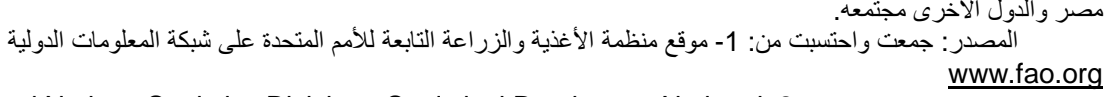

United Nations Statistics Division, Statistical Databases, National 2

Accounts Main Aggregates Database

جدول رقم (4): مصفوفة معاملات الارتباط البسيط (فى الصورة كلية) للعوامل المحددة لصادرات

\begin{tabular}{|c|c|c|c|c|c|c|c|c|c|c|}
\hline & $Y$ & $X_{1}$ & $X_{2}$ & $X_{3}$ & $\mathrm{X}_{4}$ & $X_{5}$ & $\mathrm{X}_{6}$ & $X_{7}$ & $X_{8}$ & $X_{9}$ \\
\hline$Y$ & 1 & & & & & & & & & \\
\hline$X_{1}$ & -0.451 & 1 & & & & & & & & \\
\hline$X_{2}$ & -0.550 & 0.392 & 1 & & & & & & & \\
\hline$X_{3}$ & -0.267 & 0.354 & 0.432 & 1 & & & & & & \\
\hline$X_{4}$ & -0.151 & 0.317 & 0.359 & 0.292 & 1 & & & & & \\
\hline$X_{5}$ & -0.199 & 0.606 & 0.558 & 0.769 & 0.552 & 1 & & & & \\
\hline$X_{6}$ & -0.294 & 0.048 & -0.551 & 0.019 & 0.163 & 0.045 & 1 & & & \\
\hline$x_{7}$ & -0.862 & 0.475 & 0.300 & 0.059 & -0.146 & 0.095 & -0.235 & 1 & & \\
\hline$X_{8}$ & -0.556 & 0.567 & 0.201 & -0.223 & -0.154 & -0.012 & -0.029 & 0.798 & 1 & \\
\hline$X_{9}$ & -0.278 & 0.544 & 0.602 & 0.646 & 0.867 & 0.867 & 0.024 & 0.022 & -0.048 & 1 \\
\hline
\end{tabular}

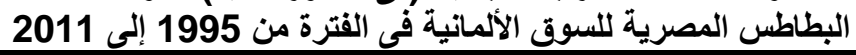

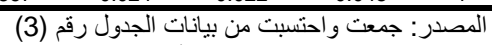

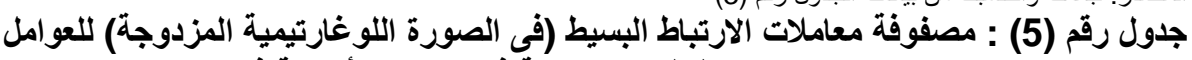

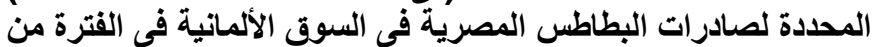

(2011 -1995)

\begin{tabular}{|lcccccccc|}
\hline & $\log Y$ & $\log X_{1}$ & $\log X_{2}$ & $\log X_{3}$ & $\log X_{4}$ & $\log X_{5}$ & $\log X_{6}$ & $\log X_{7}$ \\
\hline $\log Y$ & 1.000 & & & & & & \\
$\log X_{1}$ & -0.384 & 1.000 & & & & & \\
$\log X_{2}$ & -0.498 & 0.514 & 1.000 & & & & \\
$\log X_{3}$ & -0.281 & 0.411 & 0.475 & 1.000 & & & \\
$\log X_{4}$ & 0.034 & 0.355 & 0.460 & 0.350 & 1.000 & & \\
$\log X_{5}$ & -0.106 & 0.634 & 0.610 & 0.743 & 0.596 & 1.000 & \\
$\log X_{6}$ & 0.499 & 0.052 & -0.512 & 0.004 & 0.146 & -0.038 & 1.000 & \\
$\log X_{7}$ & -0.813 & 0.528 & 0.293 & 0.090 & -0.131 & 0.087 & -0.215 & 1.000 \\
$\log X_{8}$ & -0.515 & 0.577 & 0.194 & -0.190 & -0.125 & -0.002 & -0.028 & 0.819 \\
$\log X_{9}$ & -0.121 & 0.563 & 0.668 & 0.648 & 0.902 & 0.857 & 0.026 & 0.021 \\
\hline
\end{tabular}

المصدر: جمعت و احتسبت من بيانات جدول رقم (3)

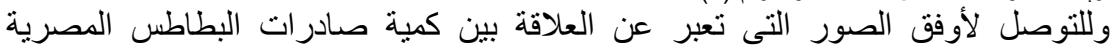

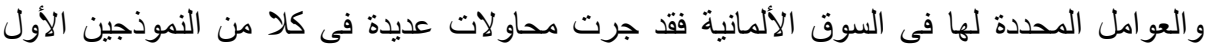

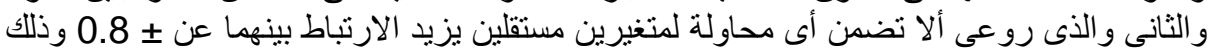

لتجنب مشكلة الازدو اج الخطى الانى.

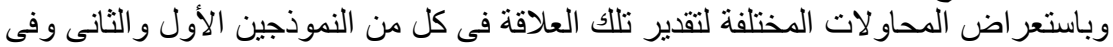
كل من الصيغة الخطية واللو غاريتمية المزدوجة كانت أوفق هذه المحاو لات الته على النحو التالى: 
نتائج تقدير النموذج الأول: باستخدام أسلوب الانحدار المتغير فى الصورة الصورة الخطية

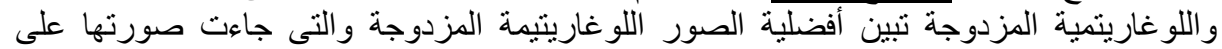
$\quad$ (1.996-)

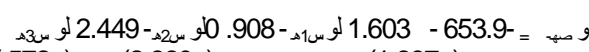
النحو التالى: التو $(.572-) \quad(2.360-)$

(1.897- ) $133.75+$ * $(2.400)$

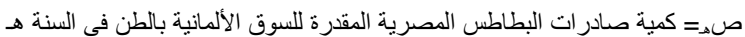

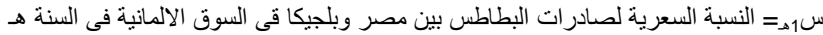

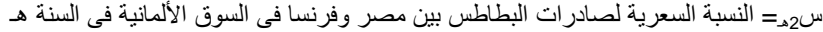

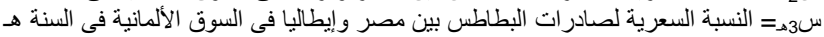

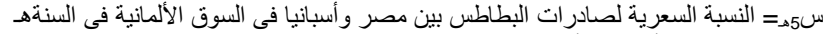
س6هـ= عدد سكان ألمانيا بالألف نسمة فى السنة هـ النه

17 ، ، 2 ، 1 - 1

وتثنير نتائج التقدير إلى أن النموذج الموضح بالمعادلة السابقة معنوى إحصائيا عند مستوى

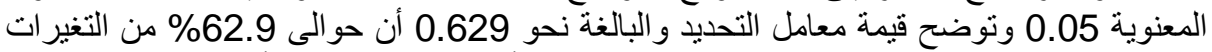

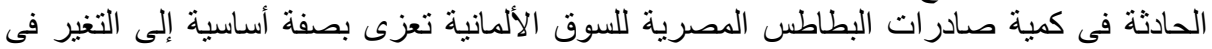

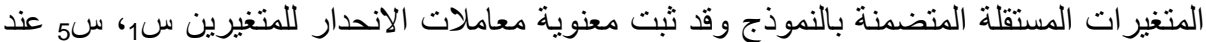

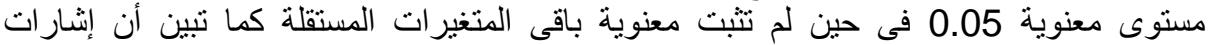

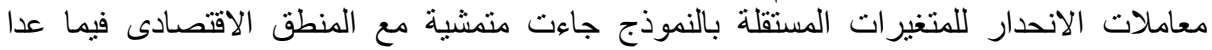

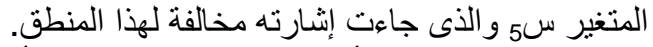

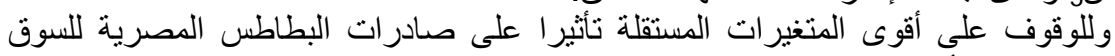

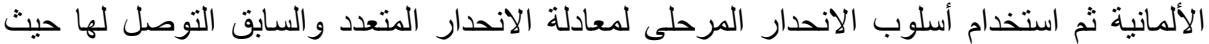

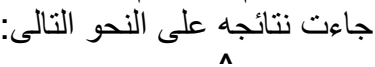

(4)

$$
R^{2}=0.249
$$

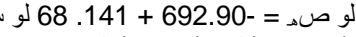
* $(2.231) *(2.217-)$

$$
\mathrm{F}=4.978^{* *} \quad \text { D.W. }=0.900
$$

وتثير نتائج التقدير للمعادلة (4) أنها مقبولة وفقا للمنطق الإحصائى والاقتصادى حيث ديث

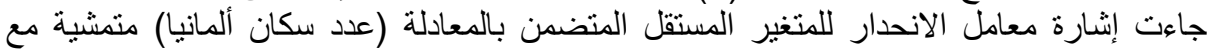

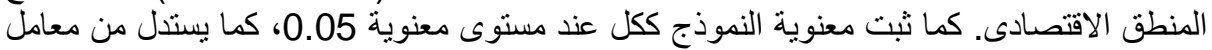

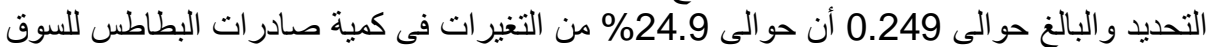

الألمانية تعزى لمتغير عدد سكان ألمانيا. وقد ثبت معنى

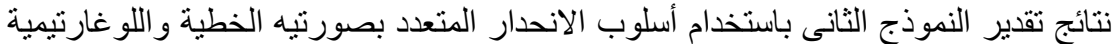

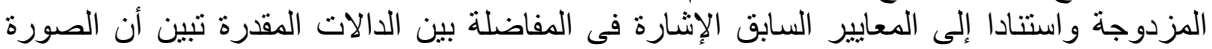

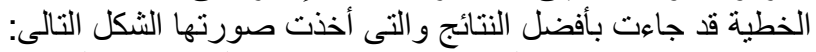
(5)

$$
R^{2}=0.267
$$

$\mathrm{F}=2.55$ $(0.583-) \quad *(2.196) *(2.182-)$

صد = الكمية المقدرة لصادرات البطاطس الدصرية للسوق الألمانية بالطن فى السنة (هـ)

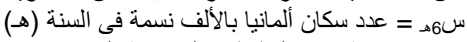
سوهـ = نسبة سعر البطاطس المصرية المصدرة من الأف مصر المنة (هـ) سعر تصدير ها من الدول المنافسة الأخرى فى السوق الألمانية فى السنة 
وللوقوف على أقوى المتغيرات المستقلة تأثيرا على كمية الصادرات المصرية من البطاطس للسوق الألمانية تم استخدام أسلوب الانحدار المرحلى للمعادلة السابقة (5) حيث جاءت نتائجه على النحو النالى:

(6) لو صد = -692.900 + 141.68 لو س

$R^{2}=0.249 \quad \quad *(2.231){ }^{*}(2.217-)$ D.W. $=0.900$

وتبين نتائج التقديرات للمعادلة (6) أنها مقبولة من الناحية الاقتصادية والإحصائية حيث

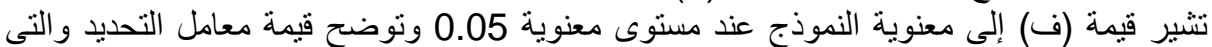

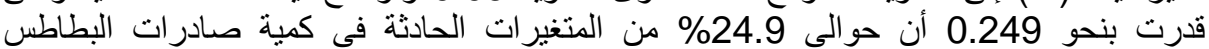
المصرية للسوق الألمانية تعزى بصفة أساسية إلى متغير عدد سكان ألمانيا. وقد ثبت معند منوية هذات البطان

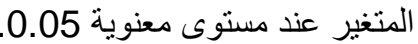

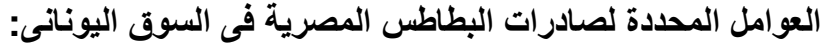

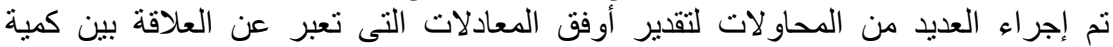

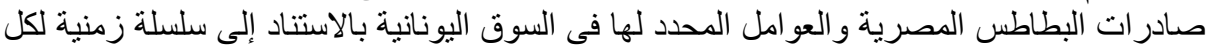

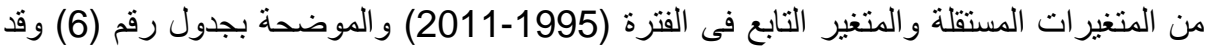
تمت هذه المحاو لات من خلال النموذجين التاليين:

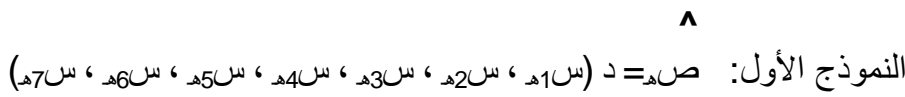

$$
\begin{aligned}
& \Lambda \\
& \text { النموذج الثانى: صله= د (س6ه ، س7هـ ، س8ه ، سوهـ ) } \\
& \text { حيث تشير: }
\end{aligned}
$$

صهـ = الكمية المقدرة لصادرات البطاطس المصرية بالطن للسوق اليونانية فى السنة هـ

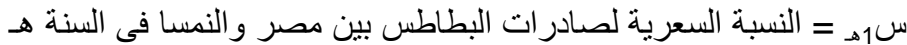

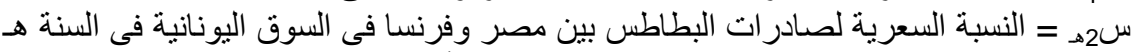

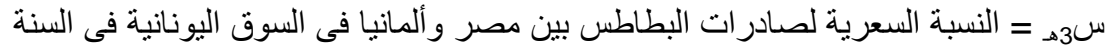

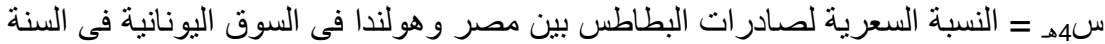

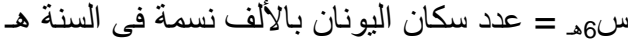
س7هـ = نصيب الفرد في اليونان بالدونان لار من النان الناتج المحلى الإجمالي بالأسعار الثابتة (باعتبار عام

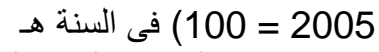

س8هـ = سعر صرف الدولار بالجنيه المصرى فئ في السنة هـ

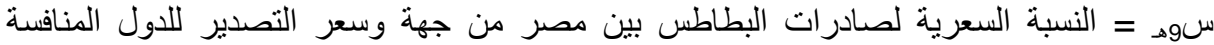

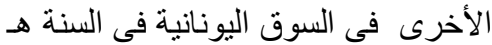

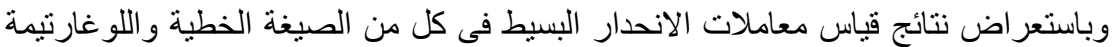

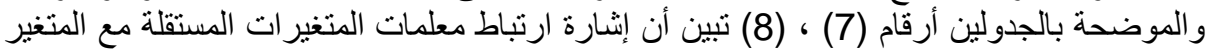

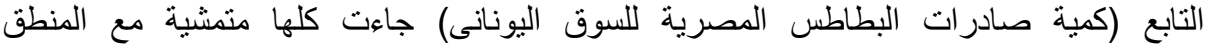

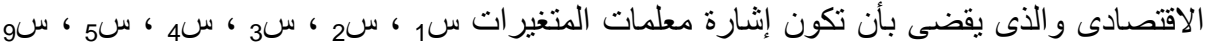

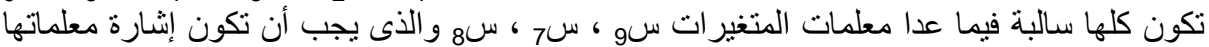
ذات إثشارة موجبة.

جدول رقم (6): العوامل المحددة لصادرات مصر من البطاطس فى السوق اليونانى فى القترة ( (2011 - 1995 


\begin{tabular}{|c|c|c|c|c|c|c|c|c|c|c|}
\hline \multirow{2}{*}{ اللبطاطسة السعرية } & \multirow{2}{*}{ سبر صرف الدولار } & \multirow{2}{*}{ نصيب الفيونى (1) } & \multirow{2}{*}{ بالأف نسمة } & \multicolumn{5}{|c|}{ النسبة السعرية لصادرات البطاطس في السوق اليونانية بين } & \multirow{2}{*}{ الصادرات } & \multirow[b]{2}{*}{ 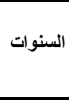 } \\
\hline & & & & مصر / هولندا & 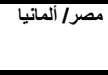 & مصر/ فرنسا & مصر|| بلجيكا & النمر / & & \\
\hline 0.606852 & 3.392 & 15577.4 & 10672 & 0.477535 & 0.771784 & 0.486911 & 1.081395 & 0.791489 & 41941 & 1995 \\
\hline 0.438636 & 3.392 & 15817.3 & 10758 & 0.271449 & 0.672474 & 0.313312 & 0.584848 & 1.054645 & 62902 & 1996 \\
\hline 0.823333 & 3.389 & 16277.6 & 10834 & 0.651715 & 1.364641 & 0.83166 & 0.925094 & 1.635762 & 24238 & 1997 \\
\hline 0.884615 & 3.388 & 16727.9 & 10897 & 0.674944 & 1.328889 & 1.132576 & 1.099265 & 1.261603 & 52492 & 1998 \\
\hline 1.203390 & 3.395 & 17219.3 & 10948 & 0.771739 & 1.543478 & 1.484321 & 0.918103 & 1.638462 & 32694 & 1999 \\
\hline 1.115830 & 3.472 & 17926.4 & 10987 & 0.793956 & 1.926667 & 1.632768 & 1.497409 & 1.876623 & 9577 & 2000 \\
\hline 1.112403 & 3.973 & 18634.7 & 11013 & 0.706897 & 1.594444 & 1.406863 & 0.834302 & 1.420792 & 2579 & 2001 \\
\hline 1.010345 & 4.500 & 19252.9 & 11026 & 0.687793 & 1.436275 & 1.140078 & 0.658427 & 1.331818 & 45314 & 2002 \\
\hline 1.114695 & 5.851 & 20386.2 & 11032 & 0.653361 & 1.054237 & 1.043624 & 0.676087 & 0.906706 & 32123 & 2003 \\
\hline 0.839535 & 6.196 & 21270.8 & 11035 & 0.659963 & 1.058651 & 0.891358 & 0.608769 & 1.211409 & 63431 & 2004 \\
\hline 0.821990 & 5.789 & 21742.0 & 11042 & 0.675269 & 1.043189 & 1.029508 & 0.666667 & 1.371179 & 49527 & 2005 \\
\hline 0.863830 & 5.733 & 22916.7 & 11053 & 0.6496 & 0.983051 & 1.082667 & 0.451613 & 1.100271 & 50896 & 2006 \\
\hline 0.737785 & 5.635 & 23697.0 & 11067 & 0.586788 & 1.247934 & 0.864504 & 0.442383 & 1.247934 & 65344 & 2007 \\
\hline 0.729345 & 5.433 & 23611.9 & 11083 & 0.570156 & 1.193473 & 1.057851 & 0.549356 & 1.35809 & 70271 & 2008 \\
\hline 0.572230 & 5.545 & 22840.4 & 11098 & 0.657005 & 0.980769 & 1.111717 & 0.415327 & 1.467626 & 68302 & 2009 \\
\hline 0.671692 & 5.623 & 21687.8 & 11110 & 0.627543 & 0.853417 & 1.083784 & 0.503769 & 0.79249 & 59539 & 2010 \\
\hline 1.237347 & 5.933 & 20130.4 & 11119 & 0.738542 & 1.111285 & 1.387476 & 0.728674 & 1.565121 & 52244 & 2011 \\
\hline
\end{tabular}

\begin{tabular}{|c|c|c|c|c|c|c|c|c|c|c|}
\hline & $Y$ & $X_{1}$ & $\mathrm{X}_{2}$ & $X_{3}$ & $\mathrm{X}_{4}$ & $X_{5}$ & $X_{6}$ & $X_{7}$ & $\mathrm{X}_{8}$ & $X_{9}$ \\
\hline$Y$ & 1.000 & & & & & & & & & \\
\hline$x_{1}$ & -0.395 & 1.000 & & & & & & & & \\
\hline$x_{2}$ & -0.688 & 0.421 & 1.000 & & & & & & & \\
\hline$x_{3}$ & -0.466 & 0.637 & 0.326 & 1.000 & & & & & & \\
\hline$X_{4}$ & -0.676 & 0.776 & 0.601 & 0.756 & 1.000 & & & & & \\
\hline$X_{5}$ & -0.453 & 0.595 & 0.322 & 0.907 & 0.714 & 1.000 & & & & \\
\hline$X_{6}$ & 0.223 & 0.195 & -0.478 & 0.597 & 0.169 & 0.554 & 1.000 & & & \\
\hline$x_{7}$ & 0.515 & -0.092 & -0.704 & 0.178 & -0.167 & 0.184 & 0.841 & 1.000 & & \\
\hline$X_{8}$ & 0.521 & -0.247 & -0.713 & 0.068 & -0.367 & 0.151 & 0.782 & 0.885 & 1.000 & \\
\hline$X_{9}$ & -0.618 & 0.498 & 0.394 & 0.801 & 0.692 & 0.797 & 0.336 & -0.091 & -0.005 & 1.000 \\
\hline
\end{tabular}

المصدر: جمعت وحسبت من نفس المصدر لجدول رقم (3) 


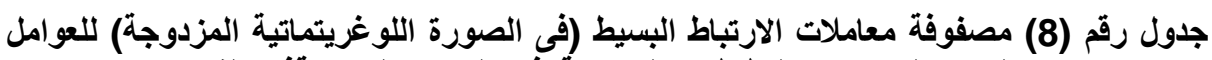

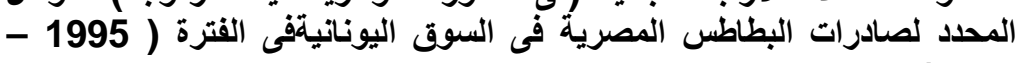

(2011

\begin{tabular}{|c|c|c|c|c|c|c|c|c|c|c|}
\hline & $\log Y$ & $\log X_{1}$ & $\log X_{2}$ & $\log X_{3}$ & $\log X_{4}$ & $\log X_{5}$ & $\log X_{6}$ & $\log X_{7}$ & $\log X_{8}$ & $\log X_{9}$ \\
\hline $\log Y$ & 1.000 & & & & & & & & & \\
\hline $\log X_{1}$ & -0.339 & 1.000 & & & & & & & & \\
\hline $\log X_{2}$ & -0.544 & 0.320 & 1.000 & & & & & & & \\
\hline $\log X_{3}$ & -0.372 & 0.546 & 0.178 & 1.000 & & & & & & \\
\hline $\log X_{4}$ & -0.598 & 0.759 & 0.500 & 0.755 & 1.000 & & & & & \\
\hline $\log X_{5}$ & -0.323 & 0.489 & 0.247 & 0.938 & 0.725 & 1.000 & & & & \\
\hline $\log X_{6}$ & 0.086 & 0.233 & -0.517 & 0.694 & 0.256 & 0.578 & 1.000 & & & \\
\hline $\log X_{7}$ & 0.329 & -0.025 & -0.755 & 0.361 & -0.052 & 0.296 & 0.865 & 1.000 & & \\
\hline $\log X_{8}$ & 0.411 & -0.194 & -0.739 & 0.239 & -0.255 & 0.228 & 0.796 & 0.907 & 1.000 & \\
\hline $\log X_{9}$ & -0.489 & 0.468 & 0.418 & 0.803 & 0.753 & 0.807 & 0.380 & 0.017 & 0.047 & 1.000 \\
\hline
\end{tabular}

المصدر: جمعت واحتسبت من نفس المصدر لجدول رقم (3)

وقد جرت عدة محاو لات لكل من النموذجين الأول والثانى فى الصورة الخطية و اللو غاريتيمة

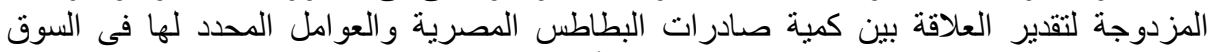

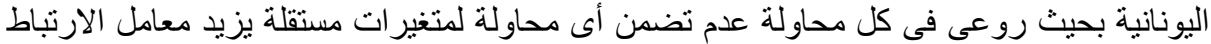

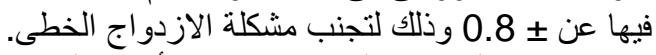

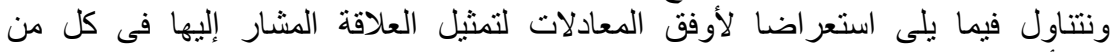

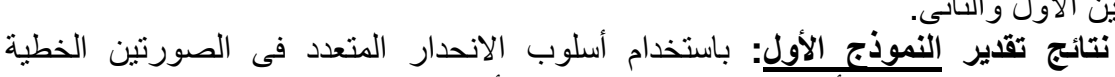

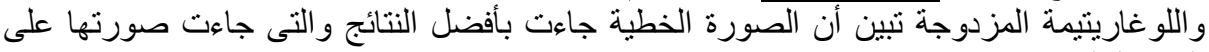

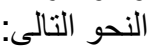

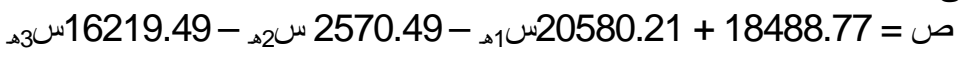
(0.880-)
(0.108-)
(1.140)
(.368)

(7) $3.306+38213.39$

$$
\begin{array}{lll}
\mathrm{R}^{2}=0.682 & \mathrm{~F}=4.710^{\star} & (1.638-) \\
& \mathrm{D} . \mathrm{W}=2.508
\end{array}
$$

$$
\text { حيث تشبر: }
$$

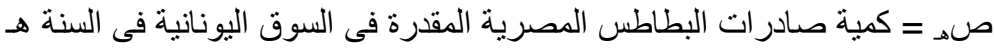

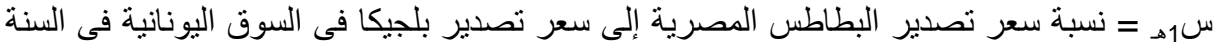
س2هـ = نسبة سعر تصدير البطاطس المصرية إلى سعر تصدير الدانمارك فى السوق اليونانية فى س3ه= نسبة سعر تصدير البطاطس المصرية إلى سعر تصدير فرنسا فى السوق اليونانية فى السنة 
س4هـ = نسبة سعر تصدير البطاطس المصرية إلى سعر تصدير هولندا فى السوق اليونانية فى السنة

$$
\text { هـ. }
$$

س7هـ = سعر صرف الدو لار بالجنيه المصرى فى السنة هـ ـ الفئ

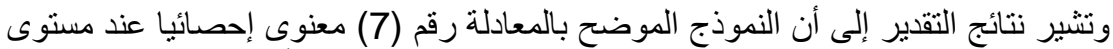

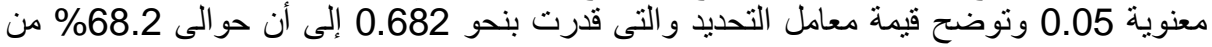

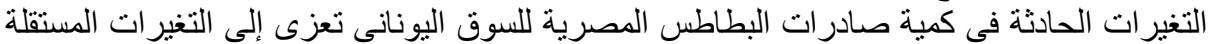

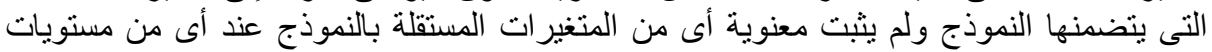

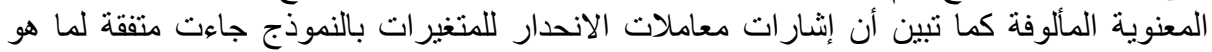

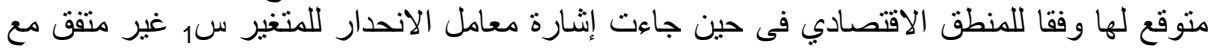
وللوقوف على أقوى المتغيرات المستقلة تأثبر على صادرات البطاطس المصرية فى السوق هذا المنطق.

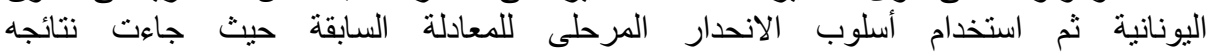
على النحو النتالى:

$$
\begin{array}{lll}
R^{2}=0.470 & \left.F=13.515^{* *}-\right) & (7.846) \\
\text { (3) } & \text { D.W. }=2.050
\end{array}
$$$$
\text { صـ }
$$

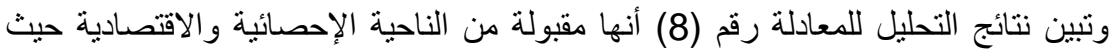

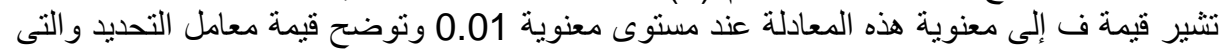

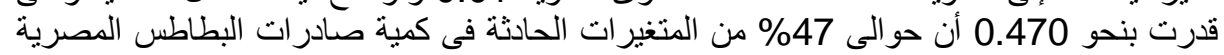

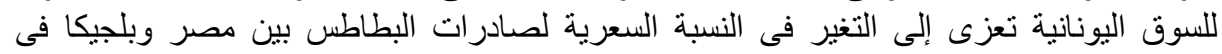

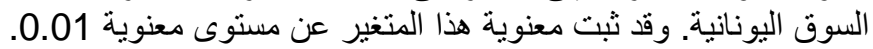

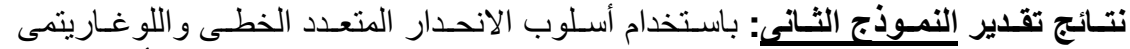

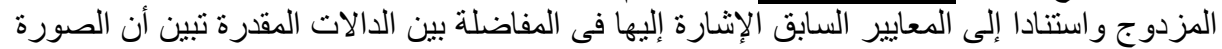
الخطية جاءت بأفضل النتائج و التى جاءت التى صورنها على الإنى النحو التالى:

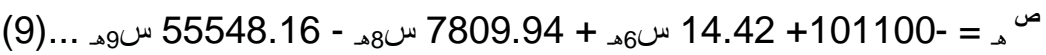

$$
\begin{aligned}
& R^{2}=0.652
\end{aligned}
$$

صـ ـ = كمية صادر ات البطاطس المصرية المقدرة بالطن للسوق اليونانى فى السنة هـ

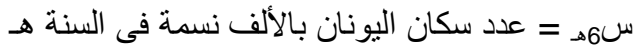

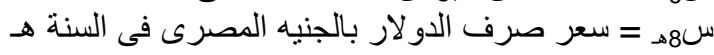
سوهـ = نسبة سعر تصدير البطاطس بين مصر و الدول المنافسة لهار لهن مجتمعة فى السوق اليونانية فى

17 السنة هـ. هـ $1=$

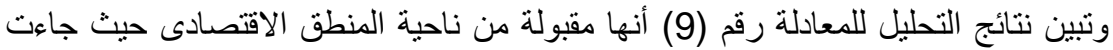

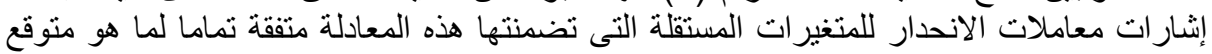

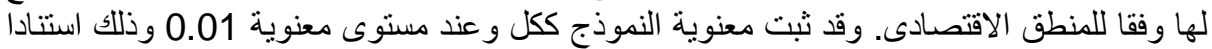

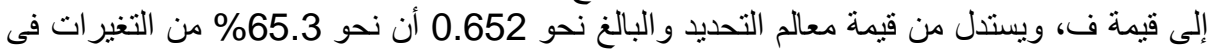

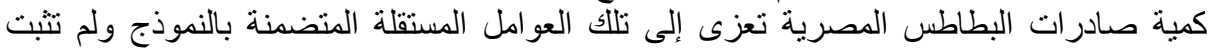

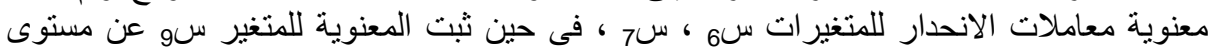




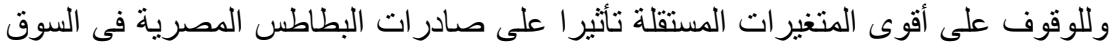

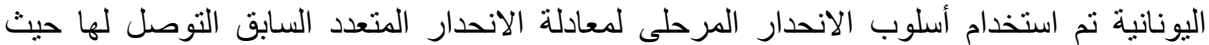
جاءت نتائجه على النحو النالى:

(10) صـ =
(3.274)
(3.895-)

$$
R^{2}=0.650 \quad F=13.012^{\star * x} \quad \text { D.W. }=2.165
$$

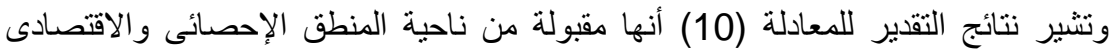

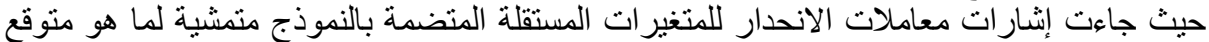

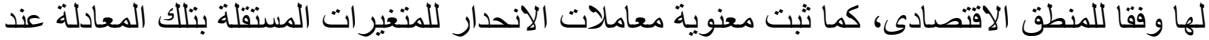

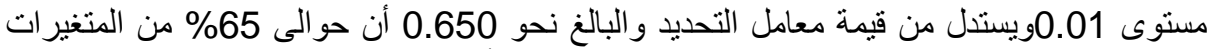

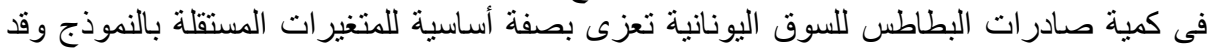

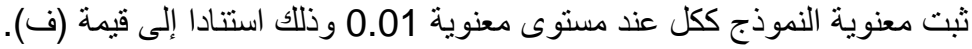

\section{الملخص والتوصيات}

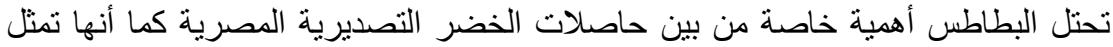

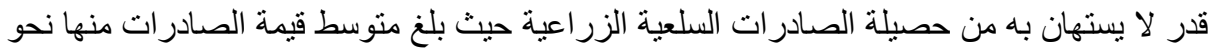

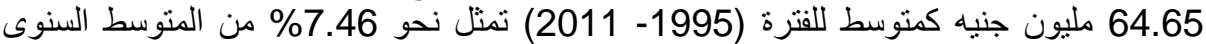

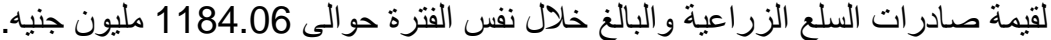

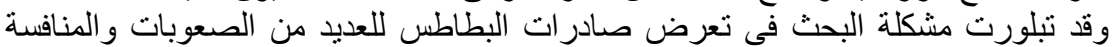

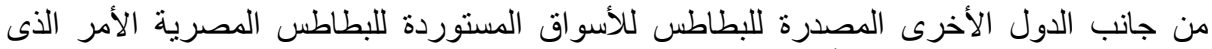

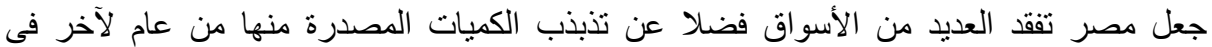

وتعتبر أسواق كل من ألمانبا، اليونان، إيطاليا، لبنان، المملكة المتحدة الأسواق الرئيسية

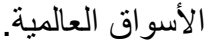

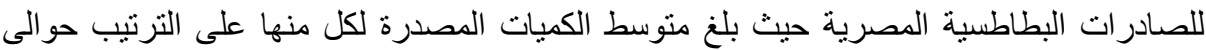

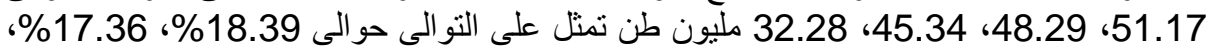

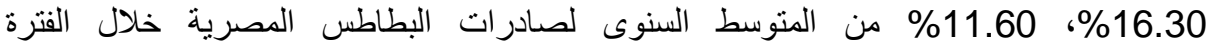

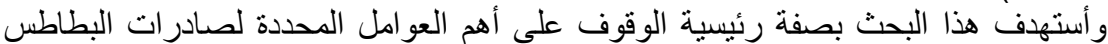
(2011-1995)

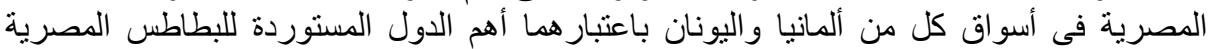

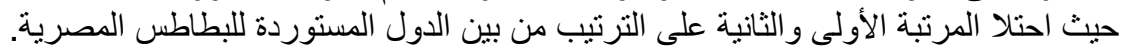

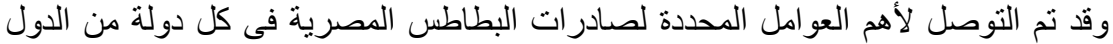

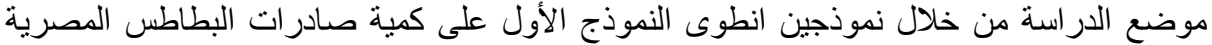

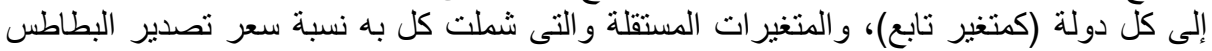

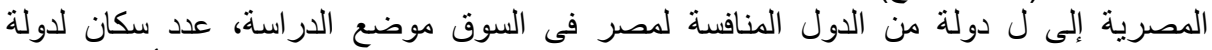

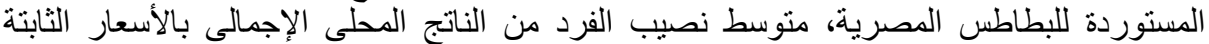

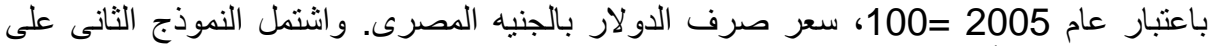

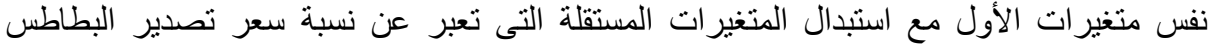

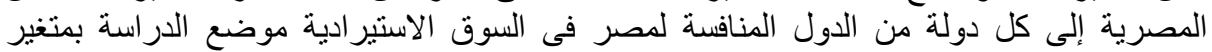

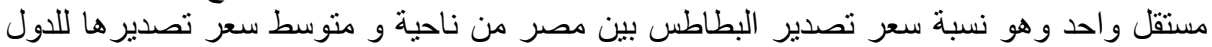
المنافسة لمصر مجتمعة فى السوق الاستير ادية للبطاطس المبن المصرية. وقد جرت العديد من المحاو لات للتوصل إلى الصيغة الصئة المناسبة التى تعبر عن العلاقة بين كمية

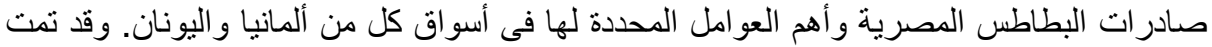

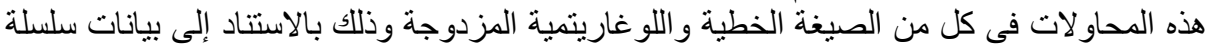


زمنية لكل من المتغير التابع والمتغيرات المستقلة فى الفترة (1995-2011). وقد استتد فى تحديد

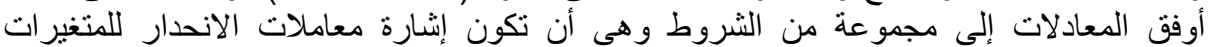

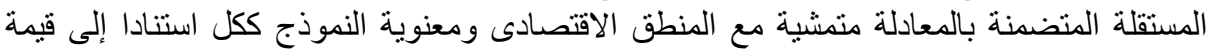

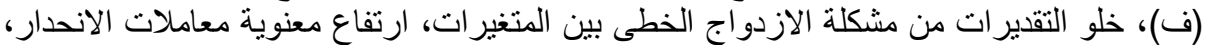
ارتفاع قيمة معامل التحديد. و أشتارت نتائج الدراسة إلى أن أقوى المتغيرات المستقلة المؤثرة على صادرات مصات مصر من

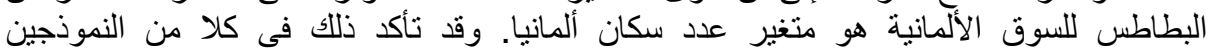

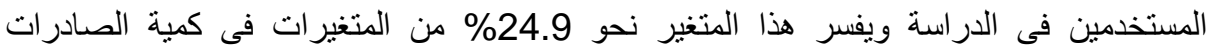

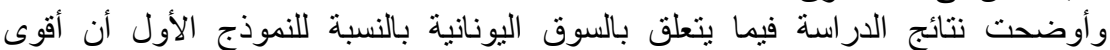

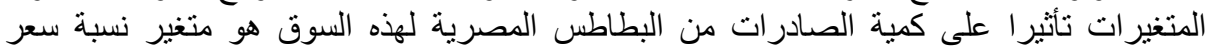

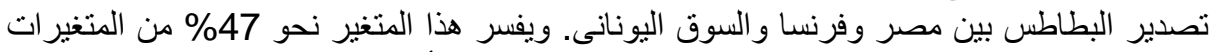

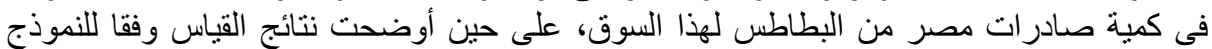

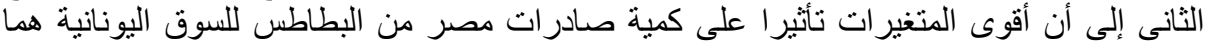

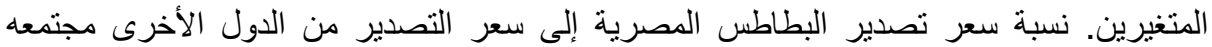

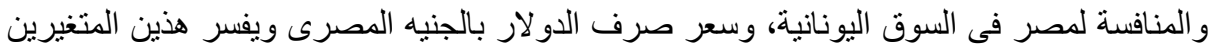

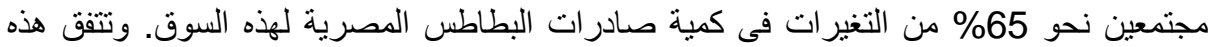

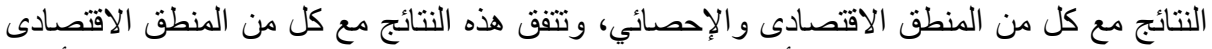

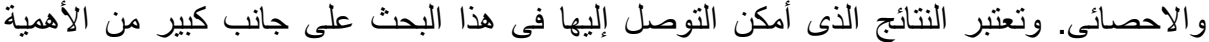
لو اضعى السياسات التصديرية المصرية لمحصول البطاطس. لتصن.

\section{المراجع}

أولا: أبحاث ورسائل علمية:

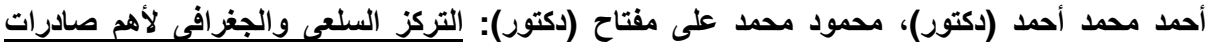

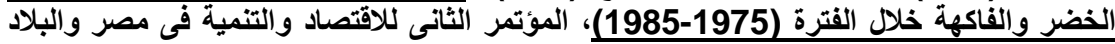

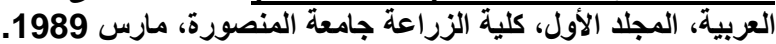

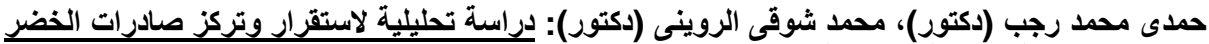

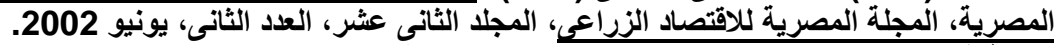

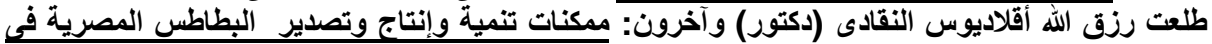

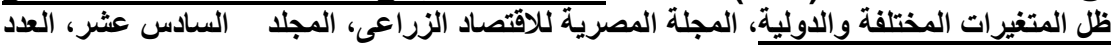
الرابع، ديسمبر 2009.

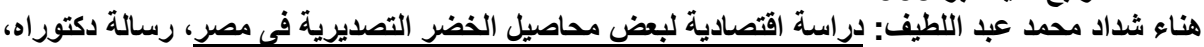

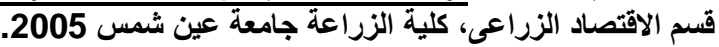

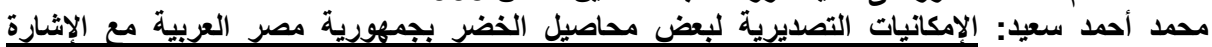

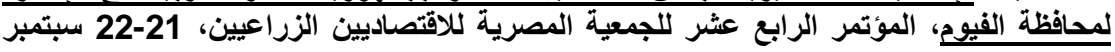
2006

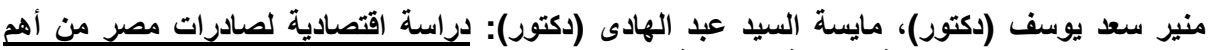

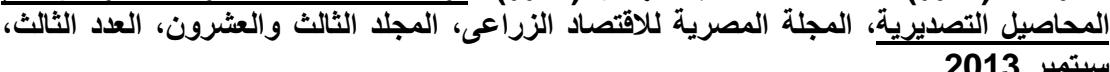

ثانيا: مواقع على شبكة المعلومات الدولئية

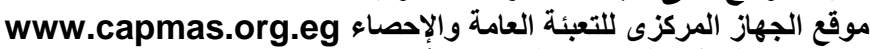

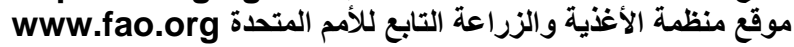
United Nations Statistics Division, Statistical Data bases, National Accounts Main Aggregates Database. 
ترانيا أحمد محد أحدد و حسين السبي سرحان

\title{
Determinants of Egypt's Potatoes Exports in the World Markets
}

\author{
Rania Ahmed Mohamed* Hussein El-Sayed Sarhan** \\ ${ }^{*}$ Dept. of Agricultural Economics, fac. of Agric. Tanta Univ. *Dept. \\ of Agricultural Economics, fac. of Agric. Ain Shams Univ.
}

\section{Summary}

Occupies potatoes special significance among the crops of vegetables export Egyptian, as it represents as much as sizeable enough of its attainment of commodity exports of agricultural $g$ with an average value of exports of which about 64.65 million pounds on average for the period ( 19952011 ) , representing approximately $5.46 \%$ of the average annual value of exports and agricultural commodities during the same period of about 1.18406 billion pounds .

The markets are Germany, Greece, Italy, Lebanon, the United Kingdom major markets for potato exports averaged quantities exported each from Egypt , about 51.17 , 48.29 , $45.34,32.28,32.28$ and

32.18 million tons Respectively represent approximately $18.39 \%, 17.36 \%$, $16.30 \%, 12.38 \%, 11.60 \%$ of the annual average of Egyptian potato exports during the period ( 1995-2011)

This research was aimed mainly stand on the most important determinants of potato exports to markets in all of Germany, Greece, as the most important importer of Egyptian potatoes occupied the place where the first and second, respectively, among the countries importing Egyptian potatoes

Has been reached in this search for the most important determinants of Egyptian potato exports in each of the countries under study through two models. first model included the amount of potato exports to each country (as the dependent variable), and the independent variables, which expresses the ratio of the export price of Egyptian potatoes to each State competition for Egypt in the market under study, and the population of the state of imported Egyptian potato, average per capita GDP total fixed prices as the year 2005 $=100$

, The dollar exchange rate in Egyptian Pounds. And included a second model on the same variables, the first model with the replacement of the independent variables, which expresses the ratio of the export price of Egyptian potatoes to each State competition for Egypt in the market import under study variable independently and one which is the proportion of the export price of potatoes between Egypt on the one hand and the average price of exported from competitor countries Egypt's combined market import of Egyptian potatoes

There have been many attempts to reach an appropriate formula that expresses the relationship between the amount of exports of Egyptian 
potatoes and the most important determinants in all markets of Germany, and Greece, as the most important export markets for Egyptian potatoes. Have been attempts in both linear and logarithmic formula and double that on the basis of time-series data for each of the dependent variable and the independent variables in the period (1995 - 2011)

It was based on identifying more satisfactory equations to a set of conditions which can be signs of regression coefficients for the independent variables included equation consistent with the logic of economic, moral model as a whole, based on the value of (f), free estimates of the problem of the link -paced multi between variables Independent included the relationship , high spirits partial regression coefficients based on the values of $(t)$, the high value of the coefficient of determination

The results of the study showed that the most powerful independent variables affecting Egypt's exports of potatoes for the German market is a variable number of the population of Germany has been confirmed in both models of the users in the study, and this variable explains about $47.0 \%$ of the changes in the quantity of potato exports to this market. While explained the results of measurement according to the model of the second that the strongest variables impact on the amount of Egypt's exports of potatoes to market Greek two variables: the proportion of the export price of Egyptian potatoes to the export price of the other countries combined, and the competition for Egypt in the Greek market, and the dollar exchange rate in Egyptian Pounds. And these two variables together explain about $65.00 \%$ of the changes in the quantity of potato exports to this market

These findings are consistent with both the economic and statistical logic. These results are possible, which is reached in this research is of great importance for policy makers to export Egyptian potatoes 